Campos Neutrais - Revista Latino-Americana de Relações Internacionais Vol. 2, $\mathrm{N}^{\mathrm{O}}$ 2, Maio-agosto de 2020. Santa Vitória do Palmar - RS.

\title{
Aspectos jurídicos da cooperação internacional em saúde pública: um encontro necessário entre saúde, direito e relações internacionais
}

Nicole Rinaldi de Barcellos* Augusto Bacelo Bidinotto**

Resumo: Este estudo tem como objetivo analisar os aspectos jurídicos da cooperação internacional em saúde pública, abordando-se a importância desta na concretização do direito à saúde como um objetivo global. Para desenvolver o objetivo proposto, o estudo foi dividido em duas partes. Na primeira parte, propõe-se uma análise do conceito de saúde, seguida da investigação sobre o reconhecimento do direito à saúde como direito humano e fundamental. Na segunda parte, são analisados os aspectos jurídicos da cooperação internacional em saúde. Cuida-se de uma análise bibliográfica de caráter dedutivo. Conclui-se que a institucionalização da cooperação internacional em saúde pública é tema que torna necessário o encontro entre as relações internacionais, o direito e a saúde pública, em uma cooperação política, jurídica e técnica, permitindo-se o intercâmbio entre Estados e autoridades sanitárias, para que seja possível o alcance de agenda global comum no tema da saúde pública.

Palavras-chave: Direito internacional. Relações internacionais. Direito humano à saúde. Saúde pública. Cooperação internacional.

\section{International cooperation in public health: an interface between health, law, and international relations}

\begin{abstract}
This study aims to analyze the legal aspects of international cooperation in public health, addressing its role in achieving global recognition of health as a human right. To attain the proposed objective, we divided the study in two parts. The first part proposes an analysis of the concept of health, and the recognition of the right to health as a human and fundamental right. In the second part we analyze the legal aspects of international health cooperation. The study was performed using deductive methods and bibliographic analysis. We concluded that the institutionalization of international cooperation in public health is a theme that demands a convergence between international relations, law and public health, entailing political, legal and technical cooperation, allowing exchange between States and health authorities, so that it is possible to achieve a common global agenda on the topic of public health.
\end{abstract}

Keywords: International law. International relations. Human right to health. Public health. International cooperation.

"Il y a eudansle monde autant de pestes
que de guerres. Et pourtant, pestes et
guerrestrouventlesgenstoujoursaussidépo urvus".

Albert Camus, em "La peste"

\section{Introdução}

Este artigo tem como objetivo analisar os aspectos jurídicos da cooperação internacional em saúde pública, abordando-se a importância desta na concretização do direito à saúde como um objetivo global. O tema da saúde se encontra no centro da agenda política dos Estados, seja pelo fato do desafio comum que propõe aos governos nacionais, seja por ser uma

\footnotetext{
* Professora substituta do Departamento de Direito Público e Filosofia do Direito na Universidade Federal do Rio Grande do Sul (UFRGS), em Porto Alegre, Brasil. Doutoranda em Direito Internacional na UFRGS.

** Doutor em epidemiologia pela Universidade Federal do Rio Grande do Sul, em Porto Alegre, Brasil.
} 
Campos Neutrais - Revista Latino-Americana de Relações Internacionais Vol. 2, $\mathrm{N}^{\circ}$ 2, Maio-Agosto de 2020. Santa Vitória do Palmar - RS.

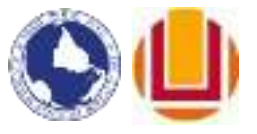

conquista relevante no campo dos direitos fundamentais. É nesse cenário que se destaca a cooperação internacional em saúde como um instrumento de alcance de uma agenda global comum a partir do intercâmbio entre Estados ou entre autoridades sanitárias.

A importância da investigação sobre o assunto é reforçada em um cenário de pandemia do COVID-19 - vírus que assola o mundo desde o princípio do ano 2020. As primeiras constatações de contaminação foram atribuídas à cidade de Wuhan, na província de Hubei, na China, mas que, rapidamente, se espalharam pelo mundo. No dia 30 de janeiro, a Organização Mundial de Saúde declarou que o surto da doença "constitui uma emergência de saúde pública de importância internacional - o mais alto nível de alerta da Organização", e em 11 de março, a COVID-19 foi caracterizada pela OMS como uma pandemia (WHO, 2020). Seguiu-se a esta declaração o reconhecimento da gravidade da crise mundial em diversos Estados.

A pandemia ora enfrentada reforça o fato de que saúde é tema que transborda as fronteiras nacionais, propondo-se como um direito humano reconhecido a ser perseguido na condição de desafio global. Com base nessa premissa, propõe-se uma investigação acerca do marco regulatório da cooperação internacional em saúde pública, em sua função de manutenção do direito humano à saúde.

O presente estudo se fundamenta em análise bibliográfica, utilizando-se o método dedutivo. Na primeira parte, propõe-se uma análise do conceito de saúde, assim como o seu reconhecimento como direito humano e fundamental, para que, na segunda parte, sejam, então, analisados os aspectos jurídicos da cooperação internacional em saúde. Será demonstrado que a cooperação internacional em saúde pública é tema que torna necessário um aprofundamento do encontro entre relações internacionais, o direito e a saúde.

\section{Tutela do direito humano à saúde como desafio global: formulação do conceito de saúde e reconhecimento nas declarações de direitos}

$\mathrm{O}$ direito à saúde constitui-se o principal direito social fundamentalmente relacionado à dignidade da pessoa humana (SARLET, 2002; CURY, 2005), cujo reconhecimento ocorreu, historicamente, em documentos internacionais e em constituições nacionais. O conceito de saúde também passou por uma evolução histórica, partindo de uma abordagem da saúde como ausência de doença para a visão ampliada de dimensões econômicas, sociais e políticas. Com base nisso, o primeiro ponto deste estudo trata dos diversos olhares sobre o conceito de saúde (tópico 1.1), para que, então, seja apresentada a saúde como um direito fundamental (tópico 1.2). 
Campos Neutrais - Revista Latino-Americana de Relações Internacionais Vol. 2, $\mathrm{N}^{\circ}$ 2, Maio-agosto de 2020. Santa Vitória do Palmar - RS.

\subsection{Diversos olhares sobre o conceito de saúde: da ausência de doença para uma} abordagem ampliada de dimensões econômicas, sociais e políticas

Apresentar um conceito de saúde é uma tarefa que comporta um grau elevado de dificuldade na medida em que o tema possui diferentes aspectos constitutivos. Inexiste uma acepção única de saúde, tornando-se necessária uma análise comparativa de diferentes olhares sobre este fenômeno, apresentados da seguinte forma: (i) saúde como ausência de doença; (ii) saúde como bem-estar na Organização Mundial da Saúde (OMS) e; (iii) conceito ampliado de saúde no Brasil. Observa-se que estas posições não são exaustivas, podendo-se falar, por exemplo, em abordagens integradas em saúde, em saúde como abertura ao risco, entre outras, de modo que a presente escolha se deu pela importância dos conceitos a este estudo (CAPONI, 1997, p. 287-307; ALMEIDA FILHO; ANDRADE, 2003, p. 101-119). Em tópico apartado, será abordada a saúde como um direito humano e fundamental.

O entendimento de saúde como ausência de doença (item i, supra) é um conceito que foi largamente difundido pela medicina e possui gênese na formação da medicina científica moderna conforme descrita por Michel Foucault (2011), que tinha, como escopo principal, a investigação e a análise da doença (BOORSE, 1977, p. 542-573). Tal abordagem conduzia o conceito de saúde a um segundo plano, à medida que esta era vista, implicitamente, como a não doença (ALMEIDA FILHO; JUCÁ, 2002, p. 879-889).

Para Georges Canguilhem, esta concepção mecanicista de saúde é criticável, pois reducionista, na medida em que é fixada nas objetividades da patologia. Segundo o autor, a clínica coloca o profissional da saúde com indivíduos completos e concretos, não com órgãos e funções, de modo que a saúde não pode ser um conceito científico (uma simples oposição com a doença), mas uma questão filosófica que recai sobre as subjetividades (2009, p. 53-55).

A compreensão da saúde como bem-estar (item ii, supra), por sua vez, foi reconhecida através do documento de constituição da OMS, de 1946, no qual a saúde foi enunciada como “[...]um completo estado de bem-estar físico, mental e social, e não apenas a ausência de doença ou enfermidade” (2014, p. 1). Esta definição afasta o caráter negativo do conceito de saúde, ao mesmo tempo em que delineia uma visão subjetiva e utópica da saúde, que, nesse caso, é impressa pela dificuldade de alcance de um "completo estado" de bem-estar pelos indivíduos.

Segundo Sandra Caponi, embora o conceito comporte críticas, estas jamais devem recair sobre o seu caráter subjetivo, pois este é um elemento inerente e inseparável da 
Campos Neutrais - Revista Latino-Americana de Relações Internacionais Vol. 2, $\mathrm{N}^{\mathrm{O}}$ 2, Maio-Agosto de 2020. Santa Vitória do Palmar - RS.

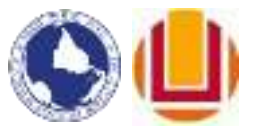

definição saúde-doença (1997, p. 207-307). Por outro lado, estabelece a autora que o conceito da OMS pode levar a práticas de controle e à exclusão do que for considerado indesejado ou perigoso, já que o conceito de bem-estar se identifica com tudo que é considerado normal em determinada sociedade, em determinado meio, de modo que a saúde não pode ser pensada como carência de meios, mas como a capacidade de enfrentá-los.

Por fim, o conceito ampliado de saúde, no Brasil (item iii, supra), é entendido através do prisma das dimensões econômica, social e política da produção da saúde e das coletividades, e o Relatório Final desta conferência (BRASIL, 1986, p. 4) estabeleceu, em seu Tema 1, a saúde como direito, em um conceito não abstrato e pautado no contexto histórico, que diz:

1 - Em seu sentido mais abrangente, a saúde é a resultante das condições de alimentação, habitação, educação, renda, meio-ambiente, trabalho, transporte, emprego, lazer, liberdade, acesso e posse da terra e acesso a serviços de saúde. É, assim, antes de tudo, o resultado das formas de organização social da produção, as quais podem gerar grandes desigualdades nos níveis de vida.

Segundo essa abordagem, a saúde passa a ser vista como uma necessidade humana de promover a saúde. No âmbito nacional, é considerado um direito dos indivíduos, tornando necessária a adoção de políticas públicas para que promovam um acesso universal e integral ao sistema de saúde (BARLETTA, 2009, p. 163-164). Entretanto, tal conceito, de forma semelhante àquele adotado pela OMS, dada a amplitude, tende a abranger, na saúde, qualquer âmbito da existência humana.

Apresentados os principais conceitos de saúde para fins do presente estudo. É importante firmar o direito à saúde como um direito humano fundamental, o que pode ser principalmente verificado através da celebração de documentos internacionais, nos quais os países comprometem-se a tutelar a saúde de forma universal.

\subsection{Reconhecimento da saúde como direito humano nas declarações internacionais de direitos e na Constituição Federal de 1988}

O direito à saúde é objeto de uma evolução histórica, cujo reconhecimento internacional positivado ocorreu somente em 1946 com a constituição da Organização Mundial da Saúde. De acordo com Fabio Konder Comparato, o sentido e a evolução dos direitos humanos é a parte mais importante da história, pois representa a revelação de que todos os seres humanos merecem igual respeito (2010, p. 13). Mas, ainda que inerentes aos seres humanos, os direitos humanos foram, internacionalmente, positivados através de 
Campos Neutrais - Revista Latino-Americana de Relações Internacionais Vol. 2, $\mathrm{N}^{\mathrm{O}}$ 2, Maio-agosto de 2020. Santa Vitória do Palmar - RS.

convenções internacionais.

Segundo Norberto Bobbio, a maioria das definições de direitos humanos é tautológica (2004, p. 17), tendo em vista que "direitos do homem são aqueles que pertencem, ou deveriam pertencer, a todos os homens, ou dos quais nenhum homem pode ser despojado". Por sua vez, o elenco de direitos constitui uma classe variável, de acordo com as mudanças das condições históricas inerentes às sociedades com as quais estes se relacionam. Segundo o autor, não é possível atribuir um fundamento absoluto a esses direitos, de modo que a grande problemática dos direitos humanos é mais filosófica que política, uma vez que não ocorre na esfera de sua fundamentação, mas na sua proteção ou tutela (BOBBIO, 2004, p. 15-45).

No campo do direito à saúde, isto é evidente. Saúde e direitos humanos são abordagens complementares na garantia do bem-estar da humanidade (MANN et al, 1993, p. 8). O diálogo acerca da combinação desses importantes temas de destaque, em debates contemporâneos, pode apresentar benefícios práticos no pensamento dos direitos à saúde acerca de patamares mínimos de tutela e de garantia.

A relação entre direitos humanos e saúde ocorre em diversas frentes, elencadas pela Organização Mundial da Saúde, como as seguintes: (i) as violações aos direitos humanos podem ter sérias consequências na saúde; (ii) a forma como os programas de saúde são planejados e implementados podem promover ou violar os direitos humanos; (iii) a vulnerabilidade e os impactos na saúde podem ser diminuídos caso sejam adotadas medidas de proteção dos direitos humanos (OMS, 2015).

Mann et al afirmam que a ligação entre as abordagens dos direitos humanos e da saúde possuem caráter complementar, com fins de tratamento do tema bem-estar humano, a saber, elas possuem uma relação inextricável (1993, p. 19-22). Segundo os autores, profissionais da saúde podem auxiliar no reconhecimento de benefícios e na identificação de custos associados com a promoção dos direitos humanos e da dignidade, sendo que o diálogo entre as disciplinas fornece um significado ao direito à saúde. Com efeito, de acordo com Amartya Sen, o direito humano à saúde ultrapassa a legislação sobre bons cuidados de saúde, identificando-se ações políticas, sociais, econômicas, científicas e culturais a serem realizadas para promover a causa da boa saúde para todos (2008).

$\mathrm{O}$ direito à saúde foi, pela primeira vez, positivado enquanto fundamental no instrumento de Constituição da Organização Mundial da Saúde, em 1946, no qual foi previsto, como segundo princípio, que "gozar do melhor estado de saúde que é possível atingir constitui um dos direitos fundamentais de todo o ser humano, sem distinção de raça, 
Campos Neutrais - Revista Latino-Americana de Relações Internacionais Vol. 2, $\mathrm{N}^{\mathrm{O}}$ 2, Maio-Agosto de 2020. Santa Vitória do Palmar - RS.

de religião, de credo político, de condição econômica ou social” (2014, p. 1).

A referida Constituição foi celebrada em 22 de julho de 1946, durante a Conferência Sanitária Internacional, firmada pelos representantes dos 61 Estados dela participantes, e entrou em vigor em 7 de abril de 1948. Veja-se que esta organização internacional foi criada no âmbito da Organização das Nações Unidas, na metade do século passado, como organismo especializado (MATTOS, 2008, p. 54-55), com fins de conduzir todos os povos a um nível de saúde mais elevado possível (OMS, 2014, p. 2).

Foi somente em 1948 que o direito à saúde passou a fazer parte de uma declaração de direitos do homem e de liberdades fundamentais no âmbito internacional. Em períodos históricos anteriores, outros documentos já haviam sido redigidos, como a Declaração de Direitos Inglesa, elaborada em 1689, e a Declaração dos Direitos do Homem e do Cidadão, da França, redigida em 1789, com fins de declarar a igualdade entre os homens. Entretanto, a Declaração Universal dos Direitos Humanos foi o primeiro documento verdadeiramente aplicável no âmbito internacional (DOUZINAS, 2009).

A Declaração Universal dos Direitos Humanos, da ONU, foi o documento que representou a internacionalização da proteção aos direitos humanos, a saber, a sua conversão em tema transcendente aos interesses puramente nacionais (PIOVESAN, 2010, p. 141).As declarações internacionais de direitos positivos surgiram após a Segunda Guerra Mundial, tendo em vista que os abusos e a violência praticados, durante este período, impulsionaram a criação de regras destinadas a garantir o respeito à dignidade humana (COMPARATO, 2010, p. 68). Este fenômeno é tão recente quanto debatido no âmbito doutrinário, pois o século XX é considerado a era dos direitos humanos, ao mesmo tempo em que é considerado o século das violações de princípios e de violências (DOUZINAS, 2009, p. 20).

Com base neste contexto histórico, importantes instrumentos de proteção dos direitos humanos foram estabelecidos no âmbito das Nações Unidas, que passaram a configurar um sistema normativo destinado à tutela destes direitos. No que tange ao tema deste estudo, observa-se que uma ideia de direito à saúde pode ser extraída do artigo 25.1. da Declaração Universal dos Direitos Humanos (ONU, 1948), que, assim, dispõe:

Artigo 25. Todo ser humano tem direito a um padrão de vida capaz de assegurar a si e a sua família saúde e bem estar, inclusive alimentação, vestuário, habitação, cuidados médicos e os serviços sociais indispensáveis, e direito à segurança em caso de desemprego, doença, invalidez, viuvez, velhice ou outros casos de perda dos meios de subsistência fora de seu controle. 
Campos Neutrais - Revista Latino-Americana de Relações Internacionais Vol. 2, $\mathrm{N}^{\mathrm{O}}$ 2, Maio-agosto de 2020. Santa Vitória do Palmar - RS.

Veja-se que a declaração faz referência a determinado padrão de vida que possa assegurar saúde aos indivíduos, não havendo uma expressa previsão quando há um direito específico e direcionado à saúde. Tal lacuna restou, de certa forma, preenchida pelas normas a ela subsequentes, adotadas no cenário internacional.

Com o advento de uma codificação complementar também celebrada no âmbito da ONU em 1966, "Pacto Internacional sobre Direitos Econômicos, Sociais", há uma nova referência ao direito à saúde, no artigo 12.1, que é mais clara e direta que a anterior, na qual é disposto que "os Estados Partes do presente Pacto reconhecem o direito de toda pessoa desfrutar o mais elevado nível possível de saúde física e mental” (ONU, 1966).

Nesse pacto, algumas obrigações de caráter prático foram estabelecidas aos Estados partes como medidas necessárias à garantia da supracitada regra geral, a saber: (i) a diminuição da mortinatalidade e da mortalidade infantil, bem como o são desenvolvimento da criança; (ii) o melhoramento de todos os aspectos de higiene do meio ambiente e da higiene industrial; (iii) a profilaxia, o tratamento e o controle das doenças epidêmicas, endêmicas, profissionais e outras; (iv) a criação de condições próprias a assegurar a todas as pessoas serviços médicos e ajuda médica em caso de doença.

Entretanto, foi somente após a declaração de Alma-Ata, de 1978, que o direito à saúde foi previsto no âmbito da Organização das Nações Unidas a partir de disposições que possuem limites mais definidos e abordam definições conceituais importantes à difusão da tutela à saúde. Veja-se que, segundo a declaração, existe o delineamento do direito à saúde como direito fundamental, em seu artigo I (ONU, 1978), nos seguintes termos:

I) A Conferência enfatiza que a saúde - estado de completo bemestar físico, mental e social, e não simplesmente a ausência de doença ou enfermidade - é um direito humano fundamental, e que a consecução do mais alto nível possível de saúde é a mais importante meta social mundial, cuja realização requer a ação de muitos outros setores sociais e econômicos, além do setor saúde.

Tal declaração possui o fim específico de expressar a urgente necessidade de uma ação conjunta de governos, bem como dos envolvidos com as áreas da saúde e da comunidade mundial, na promoção da saúde a todos os povos do mundo. A declaração cunhou a necessidade de comprometimento com os cuidados primários em saúde, estabelecendo diretrizes básicas ao seu desenvolvimento pelos Estados.

Este instrumento internacional representa um marco na tutela dos direitos à saúde e no desenvolvimento de patamares mínimos ao estabelecimento de políticas públicas de 
Campos Neutrais - Revista Latino-Americana de Relações Internacionais Vol. 2, $\mathrm{N}^{\mathrm{O}}$ 2, Maio-Agosto de 2020. Santa Vitória do Palmar - RS.

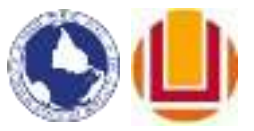

saúde e à atuação dos agentes de saúde. Ainda assim, Helena Nygren-Krug salienta que, embora a OMS tenha adotado a Declaração de Alma-Ata, a imaturidade e a controvérsia relativa ao escopo do conteúdo do direito à saúde demonstram que o tema merece uma atenta análise (2004, p. 9).

Com efeito, os dispositivos legais de proteção de direito à saúde em muito ultrapassam as discussões sobre boa gestão em saúde, justiça ou humanitarianismo, sendo consideradas obrigações de direitos humanos (BACKMAN et al, 2008). Os movimentos de saúde pública demonstram uma tendência à aplicação sistemática dos conceitos previstos em tratados internacionais em prol da preservação da vida e da dignidade humana, para as quais se faz necessária a cooperação internacional.

\section{Cooperação internacional em saúde pública para a concretização do direito} humano à saúde: evolução da interface entre relações internacionais, saúde pública e direito

A concretização do direito humano e fundamental à saúde passa pela diplomacia de saúde pública como uma expressão da solidariedade entre os povos, e materializa-se na cooperação internacional em saúde pública. O presente ponto investiga a abordagem da cooperação internacional em saúde pública em seu reconhecimento nos foros internacionais (tópico 2.1), para, então, abordar a saúde pública à luz da cooperação técnica internacional e da diplomacia da saúde global na proteção desse direito humano (tópico 2.2).

\subsection{Reconhecimento e consolidação da cooperação internacional como instrumento de aproximação dos atores internacionais no campo da saúde pública}

Como um princípio de direito internacional público, a cooperação internacional é marcada pelo dever de colaboração dos Estados na promoção do respeito e na observância dos direitos humanos (CANÇADO TRINDADE, 2017, p. 156). Este princípio foi reconhecido pela ONU na Declaração Relativa aos Princípios do Direito Internacional Regendo as Relações Amistosas e Cooperação entre os Estados Conforme a Carta da ONU (adotada na Assembleia Geral das Nações Unidas, a 24 de outubro de 1970), que estabeleceu os sete princípios de direito internacional, a saber: (i) proibição do uso ou ameaça da força; (ii)solução pacífica de controvérsias (iii) não intervenção nos assuntos internos dos Estados (iv) dever de cooperação internacional; (v) igualdade de direitos e autodeterminação dos povos; (vi) igualdade soberana dos Estados; (vii) boa-fé no cumprimento das obrigações internacionais. Desde aquela época, acentuou-se que o 
Campos Neutrais - Revista Latino-Americana de Relações Internacionais Vol. 2, $\mathrm{N}^{\mathrm{O}}$ 2, Maio-agosto de 2020. Santa Vitória do Palmar - RS.

princípio de cooperação era uma precondição para a coexistência pacífica, em constante relação com os demais princípios de direito internacional (ONU, 1970, par. 55).

Durante o século XX, a cooperação internacional fortaleceu-se como um instrumento de aproximação dos atores das relações internacionais, que ocorre em uma complexa rede de interações (AYLLÓN, 2007). A cooperação demonstra-se pelo interesse de resolução de problemas comuns, em um processo de coordenação política e jurídica, na qual ocorre um ajustamento das políticas e do comportamento dos atores internacionais para que exista um entendimento com os seus pares (KEOHANE, 1984, p. 51-52).

De acordo com Guido Soares, o direito internacional remete a uma nova orientação para as relações internacionais, que recai sobre a dimensão da cooperação (2000, p. 67). Segundo o autor, anteriormente, a cooperação era vista como corolário das boas relações entre os Estados ou como a virtude de auxiliar os Estados mais necessitados, mas o século XX a ressignificou, destacando a sua importância na saúde pública:

[...] definindo-se a cooperação como um dever nascido da necessidade de regular conjuntamente o ambiente das relações internacionais [...]no campo da saúde pública internacional e da proteção internacional do meio ambiente, a cooperação se torna uma necessidade inarredável [...]naqueles de uma consciência ética de valores globais que merecem ser preservados, como a proteção internacional da pessoa humana, a cooperação tem sido construída através de mandamentos expressos das normas internacionais, conquanto os valores humanos sejam tidos, intrinsecamente, como universais $[\ldots]$

Com efeito, a cooperação internacional é elemento essencial das relações internacionais do século XXI, a partir da construção de ações coordenadas e solidárias entre os Estados ou entre outros atores internacionais, buscando-se soluções equânimes para os grandes problemas da humanidade. Dentre as próprias finalidades da ONU, enunciadas na Carta de São Francisco, está a realização da cooperação internacional, resolvendo os problemas internacionais de ordem econômica, social, intelectual ou humanitária (artigo 1, $\S 3^{\circ}$ da Carta da ONU). A cooperação encontra-se mais evidentemente disciplinada nos artigos 55 e 56 do mesmo diploma.

A Carta de São Francisco, ao estabelecer propósitos de criar condições de estabilidade e bem-estar necessárias às relações pacíficas entre as nações, expressamente determina que as Nações Unidas favorecerão, dentre outros tópicos, a solução de problemas internacionais sanitários, assim como o respeito universal e efetivo dos direitos humanos (artigo 55 da Carta da ONU). Para o alcance desses propósitos, determina a ONU 
Campos Neutrais - Revista Latino-Americana de Relações Internacionais Vol. 2, $\mathrm{N}^{\mathrm{O}}$ 2, Maio-Agosto de 2020. Santa Vitória do Palmar - RS.

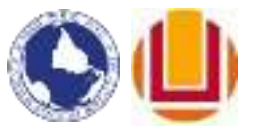

que todos os seus Estados-membros se comprometem a agir em cooperação com a organização, em conjunto ou separadamente (artigo 56 da Carta da ONU).

Com base nesses fundamentos, ao considerar o reconhecimento como um dos direitos humanos e fundamentais, é possível afirmar que o direito à saúde se beneficia de todo o arsenal jurídico constituído para a efetivação das normas de direitos humanos (SOARES, 2000, p. 70). Integrado no rol dos direitos humanos pela Declaração Universal dos Direitos Humanos de 1948, com repetição nos pactos de 1966, e em instrumentos regionais, o direito à saúde pode ser objeto de quaisquer instrumentos de cooperação destinados à proteção daqueles.

No entanto, tal fato não impediu que os debates e conferências especializadas na cooperação internacional, em matéria de saúde, em muito precederam ao reconhecimento da saúde como direito humano. Isso porque a relevância da cooperação, nessa matéria, pode ser extraída da sua importância estratégica no campo das relações internacionais, com impactos potenciais nas políticas internas dos Estados (KICKBUSCH; SILBERSHMIDT; BUSS, 2007).

Em 1851, inicia-se o movimento institucional em direção da cooperação internacional em saúde, com a Primeira Conferência Sanitária Internacional, de Paris, realizada para propor respostas cooperativas às epidemias de cólera, febre amarela e peste bubônica, que trespassavam fronteiras, atingindo diversos países entre 1830 e 1847. Seguiram-se a ela outras onze conferências sanitárias, realizadas entre 1851 e 1903, nas quais foram debatidas propostas de cooperação para o combate de doenças infecciosas (PEREIRA, 2016, p. 64).

Seguiu-se a essas iniciativas a criação de duas organizações internacionais que trataram, especificamente, do tema saúde, quais sejam: a Repartição Sanitária Panamericana, em 1902, que mais tarde se tornaria a Organização Pan-Americana de Saúde (OPAS) e a Organização Mundial da Saúde (OMS), em Genebra, em 1948. Houve, na primeira metade do século XX, a institucionalização da saúde internacional a partir da criação das principais instituições responsáveis pela regulação do tema (ALMEIDA, 2012). A OPAS foi estabelecida com o objetivo de orientar os esforços estratégicos de colaboração entre os Estados-membros e outros parceiros, no sentido de promover a equidade na saúde, combater doenças, melhorar a qualidade e elevar a expectativa de vida dos povos das Américas e a OMS, no intuito de estabelecer planos e diretrizes de saúde para o mundo, incluindo prevenção, proteção e tratamento de doenças, acesso global à assistência medica. 
Campos Neutrais - Revista Latino-Americana de Relações Internacionais Vol. 2, $\mathrm{N}^{\mathrm{O}}$ 2, Maio-agosto de 2020. Santa Vitória do Palmar - RS.

Na década de 50-60 do século XX, houve uma evolução do tema saúde nas relações internacionais, contribuindo para a formação de um direito internacional em saúde (PEREIRA, 2016, p. 65). Também, o movimento dos não alinhados, que teve, como marco principal, a Conferência de Bandung (1955), resultou em novas abordagens sobre o tema saúde, estimulando os interesses mútuos de cooperação entre os países em desenvolvimento (BUSS, FERREIRA, HOIRISCH, 2011, p. 217). À época, a agenda de política internacional se voltou para o desenvolvimento social, alçado a direito fundamental dos países em desenvolvimento.

Com o desenvolvimento social elevado a tema prioritário dos países em desenvolvimento, também reconhecido pelo Programa das Nações Unidas para o Desenvolvimento (PNUD), as questões relativas à saúde, ao meio-ambiente e ao desenvolvimento foram incluídas na agenda principal de debates internacionais. Foi nesse contexto que a saúde passou a receber tratamento como fator de desenvolvimento, de modo a tornar a longevidade e a qualidade de vida como objetivos dos Estados, efetivando-se os direitos fundamentais das pessoas.

Desde 2000, a cooperação internacional tem sido impulsionada pelos objetivos consagrados na Declaração do Milênio, adotada pela Assembleia Geral das Nações Unidas na forma de resolução (ONU, 2000). Na Declaração, foi possível a articulação entre cooperação internacional e direitos humanos, na qual, expressamente, incluiu a saúde pública (TORRONTEGUY; DALLARI, 2012).

Ademais, a partir de 2015, o direito à saúde se tornou, também, integrante dos Objetivos do Desenvolvimento Sustentável (ODSs), constando, diretamente, em 3 dos 17 Objetivos (ONU, 2020), o que impulsiona a cooperação internacional sobre o tema. A Organização Mundial da Saúde já se manifestou no sentido de que os Estados devem estreitar as relações de coordenação e intercâmbio entre autoridades sanitárias, fortalecendo a capacidade institucional dos governos (OMS, 2008).

Segundo Fidler, nos primeiros 100 anos de diplomacia internacional em saúde, a governança global, em saúde pública, foi buscada pelos Estados, pelas organizações internacionais de saúde e por outros atores não estatais, em um período marcado pelas seguintes características: (i) a tendência de os riscos de saúde se tornarem globais; (ii) a necessidade de os Estados cooperarem, com base no direito internacional, com fins de confrontar ameaças globais à saúde; (iii) o envolvimento de organizações não governamentais e de corporações multinacionais; (iv) resultados mistos alcançados por regimes jurídicos globais (2001, p. 846). 
Campos Neutrais - Revista Latino-Americana de Relações Internacionais Vol. 2, $\mathrm{N}^{\mathrm{O}}$ 2, Maio-Agosto de 2020. Santa Vitória do Palmar - RS.

Com base no exposto, demonstra-se a crescente importância da cooperação internacional em saúde pública, tanto no campo das relações internacionais quanto no do direito. Com base no aprofundamento na interação entre as disciplinas das relações internacionais, da saúde e do direito, será possível o intercâmbio entre Estados e autoridades sanitárias, buscando-se o alcance de uma agenda global comum no tema da saúde pública.

\subsection{Cooperação internacional e saúde global: um encontro necessário entre relações internacionais, saúde e direito}

No campo das relações internacionais, houve uma evolução do posicionamento mundial, no qual foi conferido um caráter menos assistencialista ao direito à saúde, observando-se, gradualmente, a transição do conceito de saúde internacional para saúde global (FEDATTO, 2015). Saúde global, nesse sentido, é entendida como os "temas de saúde que transcendem fronteiras nacionais e governos e rogam por ações das forças globais que determinam a saúde das pessoas" (KICKBUSCH, 2006).

O termo saúde global é utilizado em quatro concepções distintas, a saber, (i) como mecanismo de controle de doenças endêmicas e epidêmicas; (ii) como forma de análise dos impactos da globalização na saúde das populações; (iii) como campo de discussão de mecanismos de criação de uma globalização mais equânime; (iv) como agenda política global. Em todas essas concepções, a cooperação internacional emerge como um instrumento disponível na concretização do direito fundamental à saúde (ALMEIDA, 2012).

Conforme defende Antônio Augusto Cançado Trindade, existem áreas que requerem a cooperação dos Estados, tendo sido identificada uma intensa cooperação, nos últimos anos, nas esferas global e regional (2017, p. 157). Dentre as matérias que, necessariamente, devem buscar cooperação, inclui-se o direito à saúde, pois é tema que desafia as distinções entre o que é interno e internacional, trazendo-se à tona as já mencionadas concepções de saúde global.

Com efeito, Deisy Ventura e João Nunes destacam que uma questão de saúde global é, em primeiro lugar, aquela que está relacionada com dinâmicas, estruturas e relações políticas no plano internacional (2016). Mas não se resume a isso. Segundo os autores, também é aquela que tem um efeito internacional que vai além da simples transmissão além-fronteiras; em segundo lugar e, em terceiro lugar, podem as doenças ser consideradas questões de saúde global na medida em que impactam o desenvolvimento de 
Campos Neutrais - Revista Latino-Americana de Relações Internacionais Vol. 2, $\mathrm{N}^{\mathrm{O}}$ 2, Maio-agosto de 2020. Santa Vitória do Palmar - RS.

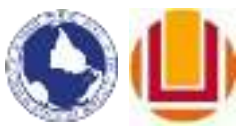

legislação e mecanismos de governança internacionais.

É, justamente, nesta terceira acepção que se revela a principal contribuição da cooperação internacional em saúde pública, visto que incentiva as diferentes formas de cooperação, especialmente na vigilância epidemiológica, mas se estendem ao comércio e à regulação alimentar (FIDLER, 2005). Nesse cenário, destaca-se a cooperação técnica internacional como um instrumento sociopolítico de desenvolvimento em saúde, relacionando-se à transferência de conhecimento e de tecnologias no campo da saúde pública.

A orientação, na cooperação técnica, relaciona-se a uma relação horizontal entre agências administrativas, com fins de compartilhamento de soluções comuns em saúde, que ultrapassa a transferência passiva de conhecimento e a torna ativa, contribuindo-se para um avanço tecnológico compartilhado, a partir de um processo de processo da “cooperação estruturante” (FERREIRA, HOIRISH, FONSECA, BUSS, 2016). Ela pode ser considerada uma ação de diplomacia em saúde, na qual se destaca a relevância da saúde em termos de política externa, de agenda política dos Estados na defesa da saúde, a partir da divulgação e do compartilhamento de conhecimentos (PEREIRA, 2016, p. 69).

A cooperação técnica internacional, em saúde, no Brasil, tem como protagonistas o Ministério da Saúde, coordenado pela Assessoria Internacional em Saúde (AISA), com o envolvimento da Fundação Oswaldo Cruz (Fiocruz), do Instituto Nacional do Câncer (INCa), da Agência Nacional de Vigilância Sanitária (Anvisa), entre outras, além da Coordenação de Aperfeiçoamento de Pessoal de Nível Superior (CAPES) e das Universidades, assim como das Secretarias Estaduais e Municipais de Saúde. Atualmente, segundo Paulo Marchiori Buss, o Brasil presta cooperação técnica em três situações, a saber(i) nas modalidades de cooperação Sul-Sul (CSS); (ii) na cooperação trilateral com países desenvolvidos ou organismos internacionais em benefício de terceiros países; e (iii) nas ações de cooperação no sentido Sul-Norte (2018).

A importância da cooperação técnica internacional em saúde é destacada no site da Agência Brasileira de Cooperação (ABC), estabelecida, em 1987, com fins de conferir maior agilidade às atividades de cooperação internacional do Brasil, como instrumento indispensável de política externa. Segundo a ABC, a cooperação técnica internacional corresponde à importante instrumento de desenvolvimento, cujos "programas implementados sob sua égide permitem transferir ou compartilhar conhecimentos, experiências e boas-práticas por intermédio do desenvolvimento de capacidades humanas e institucionais" (2020). 
Campos Neutrais - Revista Latino-Americana de Relações Internacionais Vol. 2, $\mathrm{N}^{\mathrm{O}}$ 2, Maio-Agosto de 2020. Santa Vitória do Palmar - RS.

Com base no exposto, demonstra-se que essas novas formas de cooperação renovam a interação entre saúde pública, relações internacionais e direito; mostra-se relevante reconhecer que, no campo da saúde global, emergem novos atores, para além dos Estados e das organizações internacionais, como é o caso das organizações não governamentais e das empresas transnacionais (pertencentes à indústria farmacêutica), mas, acima de tudo, do ser humano como destinatário do direito à saúde.

O direito humano à saúde encontra-se, constitucionalmente, consagrado, com fins de conformação de uma nova ordem social, mediante a garantia de políticas sociais e econômicas que visem à promoção da saúde e à redução do risco de doenças, bem como ao acesso universal (COMPARATO, 2010, p. 77-80; OMS, 2015). A efetivação desse direito vincula-se ao modelo econômico e social vigente, bem como à construção de políticas nacionais que contem com a garantia de princípios de universalidade, de integridade e de equidade (SANTOS, 1997).

É evidente que não é possível fazer com que todos os indivíduos sejam saudáveis, especialmente, se considerada a já mencionada conceituação de saúde proposta pela Organização Mundial da Saúde, relativa ao completo bem-estar físico e mental (VUORI, 1986, p. 401). Entretanto, a cooperação internacional em saúde é um poderoso instrumento na aproximação de políticas públicas e práticas no alcance da saúde.

Por isso, no campo da saúde global, mostra-se necessário o encontro entre as disciplinas relações internacionais, direitos humanos e saúde pública, cujas dinâmicas interações tendem a promover uma renovação coordenada de conceitos, no intuito da concretização do direito à saúde como um objetivo global. Como visto, ao longo do século XX e, especialmente, no século XXI, a saúde pública apresenta crescente importância na seara internacional, cuja evolução pode ser vista no próprio conceito de saúde conforme adotada por organismos internacionais, mas também no seu reconhecimento como direito humano e fundamental nos planos internacional e interno, e na sua colocação no centro da agenda de debates internacionais e da política externa dos Estados.

\section{Considerações finais}

Com a investigação proposta no artigo, demonstrou-se que o direito à saúde se encontra nacional e internacionalmente reconhecido como um direito humano e fundamental. Nesse sentido, os instrumentos internacionais de declarações de direitos são essenciais, visto que estabelecem parâmetros aos quais países devem se adequar, com fins da tutela da dignidade humana de seus cidadãos. 
Campos Neutrais - Revista Latino-Americana de Relações Internacionais Vol. 2, $\mathrm{N}^{\mathrm{O}}$ 2, Maio-agosto de 2020. Santa Vitória do Palmar - RS.

A concretização do direito à saúde possui implicações internacionais, sendo que o tratamento conceitual da matéria sofreu profundas alterações ao longo do século XX, e, especialmente no século XXI, o que levou a um necessário encontro e aprofundamento da interface entre relações internacionais, saúde pública e direito. A criação de organizações internacionais e a celebração de tratados contribuem para a aproximação e para a evolução de conceitos nas três mencionadas áreas.

Verificou-se que a institucionalização da cooperação internacional em saúde pública está prevista nos instrumentos internacionais como mecanismo necessário à materialização do direito fundamental à saúde. É nesse âmbito que tem destacado papel a regulação da cooperação técnica internacional como relevante instrumento, pois promove o intercâmbio de conhecimentos em saúde pública através de um processo horizontal e recíproco, necessário ao bom funcionamento das relações internacionais.

A institucionalização da cooperação internacional em saúde pública é tema que torna necessário o encontro entre relações internacionais, o direito e a saúde pública, em uma cooperação política, jurídica e técnica, permitindo-se o intercâmbio entre Estados e autoridades sanitárias, para que seja possível o alcance de agenda global comum no tema da saúde pública.

\section{Bibliografia}

ABC. O Brasil e a Cooperação Técnica Internacional. Disponível em: <http://www.abc.gov.br/CooperacaoTecnica/OBrasileaCooperacao>. Acesso em: 31 out. 2020

ALMEIDA, Celia. Desarrollos conceptuales em salud global y diplomacia de lasalud. TallerSalud Global y diplomacia de lasalud.Rio de Janeiro: ISAGS - UNASUR, 2012.

ALMEIDA FILHO, N.; ANDRADE, R. F. S. Holopatogênese: esboço de uma teoria geral de saúde-doença como base para a promoção da saúde. In: CZERESNIA, D.; FREITAS, C. M. (Orgs.). Promoção da Saúde: conceitos, reflexões e tendências. Rio de Janeiro: Editora Fiocruz, 2003. p. 101-119.

ALMEIDA FILHO, Naomar de; JUCÁ, Nádia. Saúde como ausência de doença: crítica à teoria funcionalista de Christopher Boorse. Ciência e Saúde Coletiva, v. 7, n. 4. Rio de Janeiro: ABRASCO, 2002. p. 879-889. Disponível em: <http://dx.doi.org/10.1590/S141381232002000400019>. Acesso em: 31 out. 2020

AYLLÓN, B. La cooperacion Internacional para el desarrollo: fundamentos y justificacion es em la perspectiva de las relaciones internacionales. Carta internacional, v. 2, n. 2, p. 25, out 2007.

BACKMAN, Gunilla; HUNT, Paul; KHOSLA, Rajat; JARAMILLO-STROUSS, Camila et al. Health systems and the right to health: an assessment of 194 countries. The Lancet, v. 372, n. 9655. London; New York; Beijing: The Lancet, 2008.

BASCH, Paul F. Textbook of International Health. Second Edition. New York; Oxford: Oxford University Press, 1999.554 p.

BARLETTA, Fabiana Rodrigues. O direito à saúde da pessoa idosa. São Paulo: Saraiva, 2010. p. 163-164. 
Campos Neutrais - Revista Latino-Americana de Relações Internacionais Vol. 2, $\mathrm{N}^{\mathrm{O}}$ 2, Maio-Agosto de 2020. Santa Vitória do Palmar - RS.

BOBBIO, Norberto. A era dos direitos. Rio de Janeiro: Elsevier, 2004. 212 p.

BOORSE, C. Health as a theoretical concept. Philosopy of Science, v. 44. Chicago: The Philosophyof Science Association, 1977. p. 542-573.

BRASIL. Relatório Final da VIII Conferência Nacional de Saúde. Brasília: Ministério da Saúde, 1986. p. 4. Disponível em: 〈http://conselho.saude.gov.br/biblioteca/Relatorios/relatorio_8.pdf〉.

Acesso em: 31 out. 2020.

BUSS, Paulo Marchiori. Cooperação internacional em saúde do Brasil na era do SUS. Ciência e saúde coletiva, v.23, n. 6. Rio de Janeiro: ABRASCO, 2018. Disponível em: < https://doi.org/10.1590/1413-81232018236.05172018>. Acesso em: 31 out. 2020.

BUSS, Paulo M; FERREIRA, José Roberto; HOIRISCH, Claudia. A saúdepública no brasil e a cooperação internacional. Revista Brasileira de Ciência, Tecnologia e Sociedade, v.2, n.2. jul/dez 2011. São Carlos: UFSCar, 2011, p.213-229.

CAMPOS, Roberta de Freitas. A cooperação internacional para o fortalecimento do direito à saúde: as estratégias da União das Nações Sul-americanas (Unasul). Tese de Doutorado (Faculdade de Saúde Pública da Universidade de São Paulo), 2018. Disponível em:

$<$ https://www.teses.usp.br/teses/disponiveis/6/6140/tde-28062018-

122046/publico/RobertadeFreitasCampos_DR_REVISADA.pdf>. Acesso em: 31 out. 2020.

CAMUS, Albert. La peste. Paris: Éditions Gallimard, 1947.

CANÇADO TRINDADE, Antônio Augusto. Princípios do direito internacional contemporâneo. 2. ed. Brasília: FUNAG, 2017.

CANGUILHEM, Georges. O normal e o patológico. 7. ed. Rio de Janeiro: Forense Universitária, 2009. $277 \mathrm{p}$.

CAPONI, Sandra. Georges Canguilhem y elestatuto epistemológico del concepto de salud. História, Ciências, Saúde - Manguinhos, v. IV (2). Rio de Janeiro: Fundação Oswaldo Cruz, 1997, p. 287-307. Disponível em:<http://dx.doi.org/10.1590/S0104-59701997000200006>. Acesso em:31 out. 2020.

COMPARATO, Fabio Konder. A afirmação histórica dos direitos humanos. 7. ed. rev. e atual. São Paulo: Saraiva, 2010. 589 p.

CURY, Ieda Tatiana. Direito fundamental à saúde: evolução, normatização e efetividade. Rio de Janeiro: Lúmen Júris, 2005.

DOUZINAS, Costas. O fim dos direitos humanos. São Leopoldo: Unisinos, 2009. 418 p.

FEDATTO, Maíra da Silva. A cooperação internacional na efetivação da saúde global: o papel do Brasil no combate ao HIV. Boletim de Economia e Política Internacional (BEPI), n. 21, Set./Dez. 2015. Disponível

em: <http://repositorio.ipea.gov.br/bitstream/11058/6476/1/BEPI_n21_Internacional.pdf>. Acesso em: 31 out. 2020.

FERREIRA, José Roberto; HOIRISCH, Claudia; FONSECA, Luiz Eduardo; BUSS, Paulo Marchiori. Cooperação internacional em saúde: o caso da Fiocruz. História, Ciências, Saúde, v.23, n.2.Manguinhos, Rio de Janeiro: Fiocruz, 2016, p.267-276.

FIDLER, D. The globalization of public health: the first 100 years of international health diplomacy. Bulletin of the WHO. Geneve: WHO, 2001.

FIDLER, D. From international sanitary conventions to global health security: the new international health regulations. Chinese Journal of International Law, v. 4, n. 2. Oxford: OUP, 2005, p. 325-392.

FOUCAULT, Michel. O nascimento da clínica. 7. ed. Rio de Janeiro: Forense Universitária, 2011. $231 \mathrm{p}$. 
Campos Neutrais - Revista Latino-Americana de Relações Internacionais Vol. 2, $\mathrm{N}^{\mathrm{O}}$ 2, Maio-agosto de 2020. Santa Vitória do Palmar - RS.

KEOHANE, R. After Hegemony: cooperation and discord in the world political economy. New Jersey: Princeton University Library, 1984.

KICKBUSCH, I. The need for a European strategy on global health. Scandinavian Journal of Public Health, v. 34, n. 6. Oxford: OUP, 2006, p. 561-565.

KICKBUSCH, I; SILBERSCHMIDT, G; BUSS, P. Global health diplomacy: the need for new perspectives, strategic approaches and skills in global health. Bulletin World Health Organization,v. 85, n. 3. Geneva: WHO, 2007, p. 230-232.

LIMA, Nísia Trindade; FONSECA, Cristina M.O.; HOCHMAN, Gilberto Trindade. A Saúde na Construção do Estado-Nacional no Brasil. In: LIMA, Nísia Trindade; GERSCHMAN, Silvia; EDLER, Flavio Coelho; SUÁREZ, Julio Manuel. Saúde e democracia: história e perspectivas do SUS. Rio de Janeiro: FIOCRUZ, 2005 (livro digital).

MANN, Jonathan; GOSTIN, Lawrence; GRUSKIN, Sofia; BRENNAN, Troyen; LAZZARINI, Zita; FINEBERG, Harvey. Health and Human Rights. Health and Human Rights Journal, v. 1, n.1. Boston: Harvard University Press, 1993. p. 7-23.

MATTOS, Adherbal Meira. Direito das Organizações Internacionais \& Direito da Integração.Rio de Janeiro: Renovar, 2008. 187 p.

NYGREN-KRUG, Helena. Health and Human Rights at the World Health Organization. Saúde e Direitos Humanos, a. 1, n. 1. Brasília: Ministério da Saúde, 2004. p.

ORGANIZAÇÃO DAS NAÇÕES UNIDAS. Carta da ONU, de 24 de outubro de 1945. Disponível em: <https://brasil.un.org/pt-br/91220-carta-das-nacoes-unidas〉. Acesso em: 9 nov. 2020.

ORGANIZAÇÃO DAS NAÇÕES UNIDAS. Declaração Universal dos Direitos Humanos.Adotada e proclamada pela resolução 217 A (III) da Assembleia Geral das Nações Unidas em 10 dez. 1948 Brasília: UNESCO, 1998. Disponível em:

<http://unesdoc.unesco.org/images/0013/001394/139423por.pdf>. Acesso em: 31 out. 2020.

ORGANIZAÇÃO DAS NAÇÕES UNIDAS. Pacto Internacional sobre Direitos Econômicos, Sociais. Adotado e aberto à assinatura, ratificação e adesão pela resolução 2200A (XXI) da Assembléia Geral das Nações Unidas, de 16 de Dezembro de 1966. Entrada em vigor na ordem internacional: 3 de Janeiro de 1976. Disponível em: <http://www.unfpa.org.br/Arquivos/pacto_internacional.pdf>. Acesso em: 31 out. 2020.

ORGANIZAÇÃO MUNDIAL DA SAÚDE. Declaração de Alma Ata. Conferência Internacional Sobre Cuidados Primários de Saúde. Alma-Ata, URSS, 6-12 de setembro de 1978. Disponível em: <http://www.who.int/publications/almaata_declaration_en.pdf >. Acessoem: 31 out. 2020.

ORGANIZAÇÃO MUNDIAL DA SAÚDE. World Health Report 2008 - Primary Health Care: Now More Than Ever. Disponível em: <http://www.who.int/whr/2008/whr08_en.pdf>. Acesso em: 31 out. 2020.

ORGANIZAÇÃO MUNDIAL DA SAÚDE. Documentos Básicos. 48 ed. Genebra: OMS, 2014, p. 1. Disponível em: <http://apps.who.int/gb/bd/PDF/bd48/basic-documents-48th-editionsp.pdf?ua=1\#page=7>. Acessoem: 31 out. 2020.

ORGANIZAÇÃO MUNDIAL DA SAÚDE. Health and Human Rights. Fact Sheet $\mathrm{n}^{\circ} 223$. December, 2015. Disponível em: <http://www.who.int/mediacentre/factsheets/fs323/en/> . Acesso em: 31 out. 2020.

ORGANIZAÇÃO MUNDIAL DA SAÚDE. A saúde e as relações internacionais: seu vínculo com a gestão do desenvolvimento nacional da saúde. Outubro, 2008. Disponível em: < $\mathrm{http} / / /$ bioeticaediplomacia.org/wp-content/uploads/2013/10/a-sade-e-as-relaes-internacionais-seuvnculo-com-a-gesto-do-desenvolvimento-nacional-da-sade-documento-e-resoluo.pdf $>$. Acesso em: 31 out. 2020.

PEREIRA, Eduardo Mazzaroppi Barão. Saúde Global e Diplomacia da Saúde: interfaces da saúde 
Campos Neutrais - Revista Latino-Americana de Relações Internacionais Vol. 2, No 2, Maio-Agosto de 2020. Santa Vitória do Palmar - RS.

com o direito e as relações internacionais. Mural Internacional, v. 7, n. 1. Rio de Janeiro: UERJ, 2016, p. 63-74.

PIOVESAN, Flávia. Direitos humanos e o direito constitucional internacional. 11. ed. rev. e atual. São Paulo: Saraiva, 2010. 608 p.

SANTOS, Boaventura de Souza. Por uma concepção multicultural de direitos humanos. Revista Crítica de Ciências Sociais, n. 48. Coimbra: Universidade de Coimbra, 1997. p. 11-32. Disponível em:

$<$ http://www.boaventuradesousasantos.pt/media/pdfs/Concepcao_multicultural_direitos_humanos_ RCCS48.PDF>. Acesso em: 31 out. 2020

SARLET. Ingo Wolfgang. Algumas considerações em torno do conteúdo, eficácia e efetividade do direito à saúde na Constituição Federal de 1988. Revista diálogo jurídico. Salvador: Bahia, 2002.

SARLET, Ingo Wolfgang; FIGUEIREDO, Mariana Filchtiner. Algumas considerações sobre o direito fundamental à proteção e promoção da saúde aos 20 anos da Constituição Federal de 1988. Revista de Direito do Consumidor, n. 67. São Paulo: Revista dos Tribunais, 2008. p. 125-172.

SEN, Amartya. Why and how is health a human right?The Lancet, v. 372, n. 9655. London; New York; Beijing: The Lancet, 2008.

SOARES, Guido F. S. O direito internacional sanitário e seus temas: apresentação de sua incômoda vizinhança. Revista de direito sanitário, v. 1, n. 1. São Paulo: USP, 2000, p. 49-88.

TORRONTEGUY, Marco Aurélio Antas; DALLARI, Sueli Gandolfi. O papel das organizações não-governamentais na cooperação internacional em saúde pública. Saúde e Sociedade, v.21, n.2.São Paulo: Universidade de São Paulo, 2012, p.314-322.

UNITED NATIONS. Principles of International Law concerning Friendly Relations and Cooperation among States in accordance with the Charter of the United Nations. New York: United Nations, 1970.

VENTURA, D. 2013. Public health and Brazilian foreign policy. Sur International Journal on Human Rights, v. 10, n. 19, p. 95-113.

VENTURA, Deisy; NUNES, João. Apresentação. Lua Nova: Revista de Cultura e Política, n. 98, Agosto 2016, p. 7-16. Disponível em:<http://www.scielo.br/scielo.php?script=sci _arttext\&pid=S0102-64452016000200007\&lng=en\&nrm=iso>. Acessoem: 09 nov. 2020.

VUORI, Hannu. Health for all, primary health care and general practitioners. Journal of the Royal College of General Pratictioners, v. 36. London: Royal College of General Pratictioners, 1986, p. 398-402.

WHO. Statement on the second meeting of the International Health Regulations (2005) Emergency Committee regarding the outbreak of novel coronavirus (2019-nCoV). 2020. Disponível em: $<\mathrm{https}: / / \mathrm{www}$.who.int/news-room/detail/30-01-2020-statement-on-the-second-meeting-of-theinternational-health-regulations-(2005)-emergency-committee-regarding-the-outbreak-of-novelcoronavirus-(2019-ncov)>. Acesso em: 31 out. 2020. 